\title{
The Development of Mobile Japanese Halal Gamification (MJHG)
}

\author{
https://doi.org/10.3991/ijim.v14i17.16653 \\ Ruzinoor Che Mat $\left({ }^{凶}\right)$ \\ Universiti Utara Malaysia, Changlun, Malaysia \\ ruzinoor@gmail.com \\ Miyata Kazunori \\ Japan Advanced Institute of Science and Technology, Nomi, Japan \\ Azman Ab. Rahman \\ Universiti Sains Islam Malaysia, Nilai, Malaysia
}

\begin{abstract}
There are projected to be over 200,000 Muslim tourists will visit Japan due to expected Tokyo Olympics 2020. But the previous study showed that the level of understanding about Muslim needs such as Halal terms still low among Japanese people. There is a technique and approach such as gamification that need by the Japanese people to fulfill this requirement. Gamification which integrating game thinking and games element has been proven to help in learning new knowledge. That is why the objective of this study discusses how to develop an application of MJHG in a smartphone-based on the android system. The MJHG was design based on a well-known visual novel concept that combining with multimedia elements included audio, animation, graphics, and image to make it more attractive and alive. All of these elements blending with the gamification elements such as quiz, rewards, badges, and feedback to make it as gamified applications. Based on all of these capabilities of MJHG, it, therefore, can help the potential user's not only Japanese people but also non-muslim to increase their level of understanding and awareness toward Halal terms.
\end{abstract}

Keywords-Gamification; Japanese; Halal; awareness; Mobile Application.

\section{Introduction}

As the report to Kim and Mercurio [1], currently, they are about 100,000 Muslims living in Japan. This number is gradually increasing from time to time. It is proven that when they visit the largest mosque in Tokyo (Tokyo Camii), they are about 500 Muslim people perform Friday prayer. There are about sixty-one mosques separate all over Japan. If this were counted, it is shown that the Muslim population in Japan is growing since it was introduced in the 1900s [2]. Interview by Kim and Mercurio [1] found that they are lack of knowledge about Muslim traditions such as Halal terms among Japanese people. Most of them are quiet when asking about religion, which needs more education about diverse practices such as Muslims at the municipal and national levels. 
The preparation for Tokyo Olympics 2020 provoked a warm welcome to Muslim tourists which responsibility of local Muslims to educated non-Muslim Japanese about Muslim faith such as Halal terms including Halal food, beverage, and meats. Based on Islamic rules Halal foods means permissible foods that Muslims are obligated to consume them [2]. In Japan, currently "Muslim friendly restaurant" is common. This means that this restaurant serves the food which does not contain pork and alcohol including alcohol beverage [3]. This kind of restaurant is very popular among Muslim tourists. Based on clear evidence, Adidaya [3] suggest that Halal is really based on personal choice and the definition of Halal in every country is still unclear including Japan. While regarding the halal meats, it's mean that the meats that produce from the animal which been slaughtered according to Islamic rites [4]. In Japan, the Halal slaughtering process and regulations are still unclear. These issues were impeding Halal from spreading more widely in Japanese society [3]. There is a technique and approach such as gamification that need by the Japanese people to solve all of these issues. As mentioned by Majuri et al. [5], gamification has become the most notable technological development which can enhance human engagement. According to Kapp [6] gamification is "using game-based mechanics, aesthetics and game thinking to engage people, motivate action, promote learning, and solve problems." In these applications, the gamification elements such as users, levels, feedback, score, and badges will be utilized. To implements this technique, tools such as mobile application which embedding gamification elements could be introduced. Recently, mobile devices are produced with the integration of various techniques with portability and mobility which encouraged users to make use of mobile devices not only to contact people but has become users' helpers, navigators, tourist guides, and others such as games [7]. The past decade has been an immense growth in the level of demands and interest in mobile computing. Users are purchasing fewer desktop computers, but have been buying new mobile technology at a tremendous rate [8]. There are two available platforms for launching this application into mobile devices, which are Android and IOS. For these applications, the Android platform was used. The focus of this study is to discuss how to develop an application of MJHG in a smartphone-based on the Android platform. This application was used to help not only Japanese people but also non-muslim to increase their level of understanding and awareness toward Halal terms. The application was called as Mobile Japanese Halal Gamification (MJHG).

\section{$2 \quad$ Literature Review}

\subsection{Halal terms}

Halal is an Arabic word, which simply means permitted or lawful. So when talking about Halal food, it means any food that is allowed to be eaten according to Islamic Law that is stated in Holy Qur'an [9]. Haram food is the opposite of the word "Halal food" where any food that contains pork or alcohol. As stated by [10], many things are Halal or Haram, but some things are not clear and questionable. This kind of item is 
often referred to as Mashbooh, which means doubtful or questionable. He listed that all foods are considered Halal except the following, which are Haram:

- Swine/pork and its by-products

- Animals improperly slaughtered or dead before slaughtering

- Animals killed in the name of anyone other than ALLAH (God)

- Alcohol and intoxicants

- Carnivorous animals, birds of prey and land animals without external ears

- Blood and blood by-products

- Foods contaminated with any of the above products

All of this statement support by Majid [11] that mentioned as Muslims occupy a quarter of the world's population, the concept of Halal and Haram are general terminologies that can be applied to every aspect of life and the market for certified halal food and products is rising strongly where it's received worldwide recognition.

\subsection{Gamification}

Gamification is an integration of game elements and game thinking in activities that are not games [12]. Games have some distinctive features, which play a key role in gamification which are users, challenges/tasks that users perform and progress towards defined objectives, points that are accumulated as a result of executing tasks, levels which users pass depending on the points, badges which serve as rewards for completing actions, ranking of users according to their achievements. Other than that, Deterding et al.'s [13] refer to gamification as a contextualizing game design outside its original domain. While Zichermann and Cunningham [14] define gamification as establishing the brand, engage users and influence their behavior by using game mechanics. As Deterding et al. [13] suggest that "gamification involves applying elements of gainfulness, gameful interaction, and gameful design with a specific intention in mind". Seaborn and Fels [15] further explain "gainfulness refers to the lived experience, gameful interaction refers to the objects, tools and contexts and gameful design refers to the practice of crafting a gameful experience". Gamification is more about motivating people to take actions perhaps in a structured way and follow specific rules to achieve variable outcomes [13]. Nevertheless, gamification differs with games at the purpose of play. Gamification focuses on changing players' behavior, engagement with their environment and co-players who may also be fellow customers or service providers towards achieving meaningful interaction and engagement and potentially achieve rewards. Many researchers has been applied gamification in their applications for engaging and attracting users for their product such as Mobile Eatery Recommendation [16], improving Jawi skills [17], and Gastronomic Questionnaires [18].

\subsection{Mobile technology}

The use of mobile devices, and particularly those with location-based services, has become pervasive. The wide distribution of mobile users with GPS, accelerometers, 
cameras, and real-time human conversations has made it possible to provide situational awareness of the real world in areas such as traffic congestion, urban networks, and WiFi conditions, as well as other geographical information services [19]. This statement support by Rude [20] which mentioned that the possession of smartphones increased from $17 \%$ to $46 \%$ from 2011 to 2016 of total households, while growing internet penetration around the world keeps growing, leading to the even higher importance of Bring Your Device (BYOD). The latest trends in new technology were the intersection of mobile computing and Internet computing. Whereby a popular concern is the interaction of information and functions on the Internet with the real world using the mobile device as a medium that emerges as next-generation mobile services related to internet computing [21].

\section{The Development Methodology}

The development of MJHG involved five majors' stage as it follows the waterfall software development life cycle. The process starts with the requirement analysis, system design, implementation, testing, and maintenance. The mobile application was developed based on multimedia elements including audio, animation, graphics, and image to become more attractive and alive. The software used in the development consist of Unity 3D 5.6.3. Besides the Android SDK, JDK and Unity Extension need to be installed on the PC to build an Android Application Package (APK) file. Then the APK file can be used in a mobile platform as an application of MJHG. Figure 1 shows the flow of each phase of development.

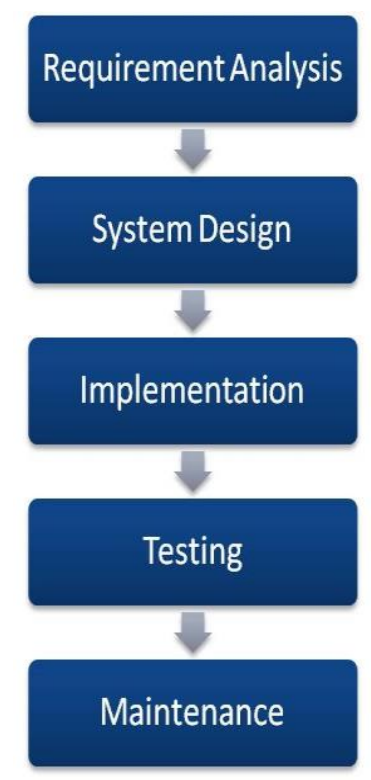

Fig. 1. Waterfall Software Development flow 


\subsection{Requirement analysis}

In these phases, a suitable title for the study was chosen. The title of this study was chosen as MJHG, which aims to explain what the mobile application is going to do. Then the objective, problem statement, project background, and scope were identified. The schedule of the study also needs to be planned as well. All related requirements regarding the mobile application to be developed were captured and documented. A survey was conducted to know the need for Japanese Halal Gamification among Japanese people. They are about 85 respondents have given feedback in this survey. The results show that there is a need for a new tool to develop such as gamification for increasing the level of awareness and understanding about Halal terms among Japanese people.

Other than that, the survey also has a question related to Halal terms including Knowledge of Halal and Haram (Non-Halal) together with Halal awareness. The results of this survey were analyses accordingly. The result helps to determine the requirement of MJHG. Based on the results, the part that needs to be focused on developing the MJHG was on the Halal foods, Halal ingredients of the beverage and also about also the meats that Haram (Non-Halal) for Muslim to be eaten. These three main parts will be focused on developing MJHG. Then the concept of MJHG was design. The visual novel concept has been chosen for developing the MJHG. This is due to the popularity of this concept among Japanese people and also in the world. In the visual novel, the storyline is very important where it was the backbone of MJHG. The script was then prepared. After the entire requirement is fulfilled, then the system design can be started.

\subsection{System design}

At these phases, the requirement specifications from requirement analysis were studied and system design was prepared. This will help in specifying hardware and system requirements. Besides that, it's also helped in defining overall system architecture. As mentioned before, the multimedia elements including audio, animation, graphics, and image were used and blended with the gamification elements (such as competition, score, feedback, and badges) for developing this system. This combination is the most important part of MJHG which can help the user to be more understanding about the MJHG. This makes the MJHG more interesting to play. Besides that, the layout of modules, low fidelity prototype design was prepared. For the low fidelity prototype, the functional and non-functional requirement is identified. Then, Unity 3D is used to design the interface. The Anime character also inserts inside the games, to make MJHG more interactive. Adobe Photoshop software used for designing and editing graphics such background of the environment. Audacity was used for editing the audio. The design of MJHG is based on a storyline where it's divided into three levels which are Level 1 (at Restaurant), Level 2 (at Supermarket) and Level 3 (at Meats Shop). Based on this storyline, the scripts were written and the flow of the games was design and setup. Then the implementation of MJHG could be started. 


\subsection{Implementation}

In these phases, a temporary prototype of MJHG based on the Android platform was developed by following the system design phase. All contents of MJHG are produced by using Unity 3D. Based on the written scripts, the development starts at the Introduction part. At this part, the main menu is set and all characters involve were insert. The narrator plays an important role in this part. When it finished, the development at level 1 (at Restaurant) could be started. At this level, the background of the restaurant environment was set and all of the related characters such as waiter and player also were set. The scripts for each character developed and compile. When level 1 is finished, level 2 (at Supermarket) were started. At level 2, the background of the supermarket environment was set and all of the related characters such as storekeeper and player also were set. The scripts for each character also developed and compiled here. When level 2 is completed, level 3 (at Meats shop) was started. At the final level, the background of the meats shop environment was set and all of the related characters such as butcher and player also were set. The scripts for each character also developed and compiled here. For each level, the interface is also design and the function of each interface was fitted together with the character and the environment. When all parts are developed and ready, they were compiled together to make a complete game of MJHG. Now the process of building the APK file can be started. As mentioned before, a temporary prototype of MJHG is based on the Android platform, so the APK file is needed to install it inside the mobile platform. The APK file is built with the minimum API level of the Android OS which is Android 4.1 "Jelly Bean" (API Level 16). After completed, the new APK file is ready to be installed and test as a temporary prototype. To share this APK file without using any play store, the cloud storage (such as Google drive) could be utilized. Due to the restriction of the Android platform, the users need to set their mobile to be accepting the apps from the "unknown device". If not, the apps could not be installed on their mobile device. After installation completed, the MJHG apps are ready to be play and test.

\subsection{Testing}

At these phases, the alteration of MJHG could be made. To make it more consistent, redesigning the interface, contents, background image, character and buttons also perform here. Each level of the games was tested. Then at the final stage, the post-integration of the entire system was tested for any faults and failures. Once the functional and non-functional testing was done, the expert evaluation was conducted to utilize the knowledge of user experience professionals in evaluating the effectiveness of the MJHG. As well as, the feedback of the weakness and acceptance of MJHG can be identified before tested by target users. After resolving errors, based on the suggestion from the expert, user evaluation was conducted to know the acceptance, usability, and engagement of users on the use of MJHG. 


\subsection{Maintenance}

This is the final phase where if there were some issues arises in the user environment of MJHG, those issues were corrected and the product was improved with better functions and performances. Maintenance was done to deliver these changes in the user environment. Some of the issues were about the language uses in MJHG. To make the MJHG broader, other than Japanese Languages, MJHG also should be available in the English Language. Other than that, more instruction was given to the user as a guide and the buttons were corrected by using suitable metaphors to enhance the usability of MJHG. The other issues could arise about the mobile platform uses for launching the MJHG. Based on the observation and study, most of the Japanese people are using Apple compare to Android. So, the MJHG should also be available to be launching on the iPhone. When this issue is solved, the MJHG could be made available to everybody, not just Japanese people.

\section{Mobile Japanese Halal Gamification}

The MJHG is developed to help the users in understanding about the Halal terms and also increase their level of awareness toward Halal terms. As mentioned before, based on the study from other researchers, the Visual Novel concepts seem to be the best solution for developing MJHG. This concept was combined with gamification elements such as competition, quiz, score, tips, and badges. The package of MJHG is developed to make it able to be installed on mobile devices. MJHG was made in the Japanese Language. This MJHG was divided into three levels which are Level 1 at the restaurants, Level 2 at the supermarket and Level 3 at meats shop. The flow of MJHG is shown in Figure 2.0. 


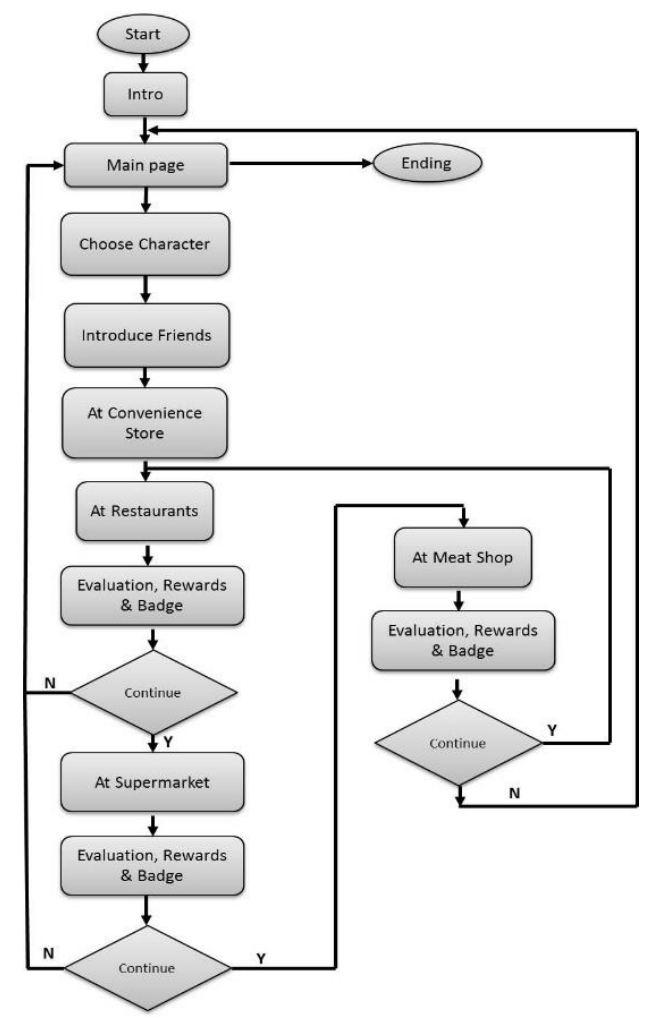

Fig. 2. The flow of MJHG 3.0

The first parts appear after the splash screen was the main menu as shown in Figure

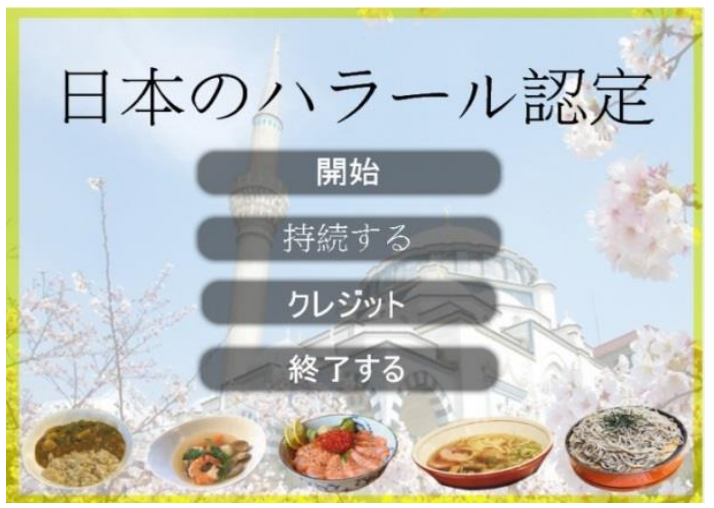

Fig. 3. Main page 
The main menu consists of the buttons "Start", "Continue", 'Credit", and "Exit". The "Start" button was for starting the game. The "Continue" button was to continue the game whenever it is saved. The "Credit" button was for displaying the credit of developer to all parties that involve in developing the game and also a credit to all resources use. The "Exit" button was to quit the game. When the users press the "Start" button, the game will start. The games start with the instruction where the player needs to read and understand on how to play the games. After that, the games began. It shows the environment of Japan Advanced Institute of Advanced Science and Technology (JAIST). Then, the player will be asked to choose their character (role) in the games either male or female (see Figure 4.0) that he/she will play. The male player is known as Mr. Nakamura and the female player known as Ms. Yuko.

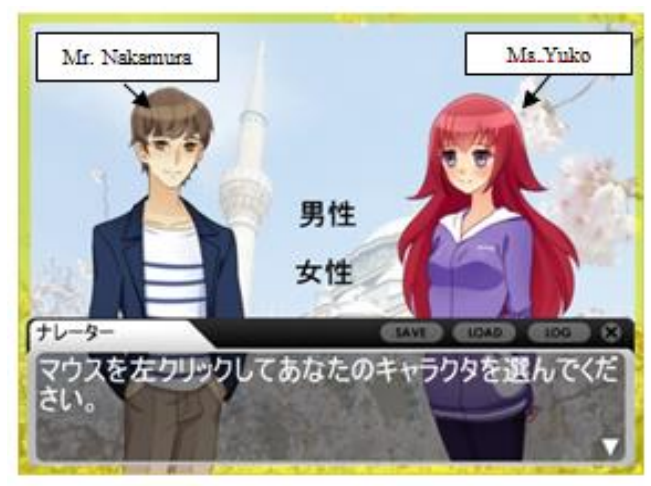

Fig. 4. Choosing a player

After that, the player chooses their character, the games continue with the introduction of the main character of MJHG which calls Mr. Fujiwara. The games were shown on the biodata of Mr. Fujiwara (see Figure 5.0).

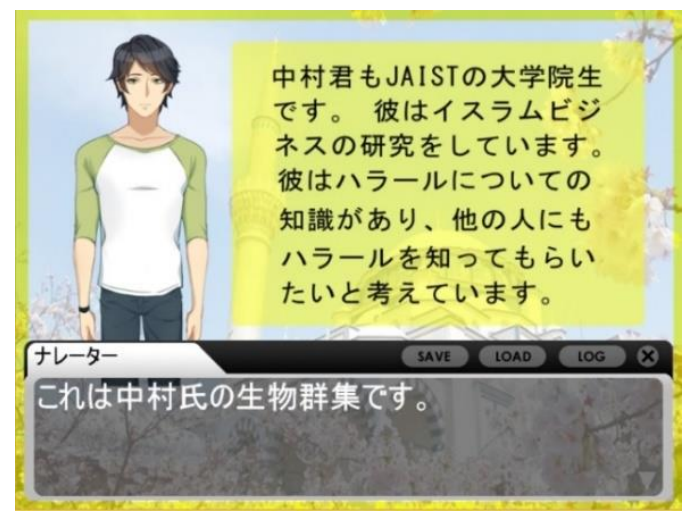

Fig. 5. Biodata of Mr. Fujiwara 
Mr. Fujiwara is the main character in these games. He's the expert in Halal and would like to share his knowledge with others. Inside the games, he will accompany the player along the way to all of the places which are restaurants, supermarkets, and meat shops (Level 1 until Level 3). But the player has a choice to stop the games at any level they like. The player is then were meets Mr. Fujiwara at Convenience Store (the commonplaces of Japanese people visit every day). They will meet here and start the conversation. When the conversation is finished, the games continued to Level 1 of the games where the player needs to go to the restaurants together with Mr. Fujiwara.

\subsection{At restaurant}

At this place, Mr. Fujiwara and the player were served by a waiter of the restaurant (see Figure 6.0). Mr. Fujiwara will offer the player to pay him a treat but the player needs to answer two questions. Here the elements of gamification which is quiz will be added. The two questions asked were regarding the Halal foods (see Figure 7.0). If the player manages to answers the question right, he will get a score as 1 and the happy sound was played. If the answer is wrong, he will get a score as 0 and the sad sound was played. For the answer correct or wrong, the results were displayed and explain why it is correct or wrong. After completing the first quiz, the waiter was serving the food that their order to them and they will eat together. The player will get Badges to show that he/she completing the first level of the games. The screen then shows a total score of the player (wrong and correct) and also the badges (value set as 1) (see Figure 8.0). The sound of completing level 1 played. In the end, the games will ask the player either to continue to the next level or the player can stop here. If the players choose to stop, the games will go back to the main page whereby the player can exit the games. If the player chooses to continue, the games were going to the next level which is at the supermarket.

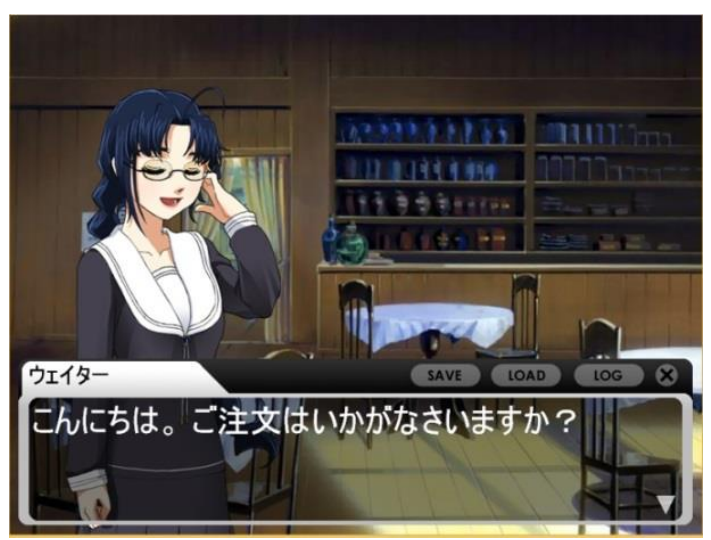

Fig. 6. Restaurants (Level 1) 


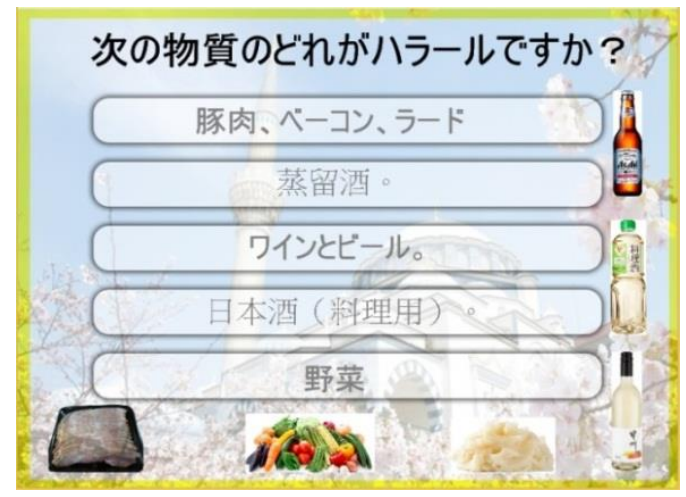

Fig. 7. Questions regarding Halal food

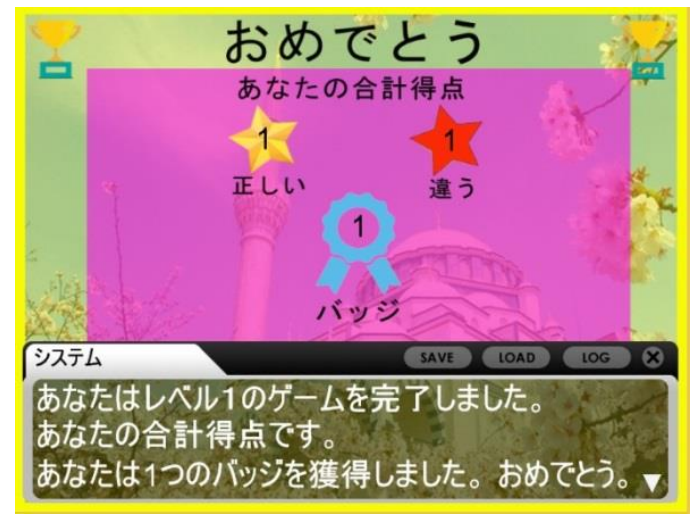

Fig. 8. Complete Level 1 of the games

\subsection{At the Supermarket}

At this place, Mr. Fujiwara and the player were served by a storekeeper of the supermarket (see Figure 9.0). Mr. Fujiwara will bring the player inside the shop but before that, he will ask two questions to the player. These two questions were regarding Halal beverages (see Figure 10.0). If the player manages to answers the question right, he will get a score as 1 and the happy sound was played. If the answer is wrong, he will get a score as 0 and the sad sound was played. For the answer correct or wrong, the results were displayed and explain why it is correct or wrong. After completing this second quiz, the storekeeper was welcoming them and allows them to enter into the supermarket. They together entered the supermarket and start shopping. Here also the player will get Badges to show that he/she completing the second level of the games. The screen then shows a total score of the player (wrong and correct) and the badges (value set as 2) (see Figure 11.0). The sound of completing level 2 played. In the end, the games will ask the player either to continue to the next level or the player can stop here. If the players choose to stop, the games will go back to the main page whereby the player can 
exit the games. If the player chooses to continue, the games were going to the next level, which is at the meat shop.

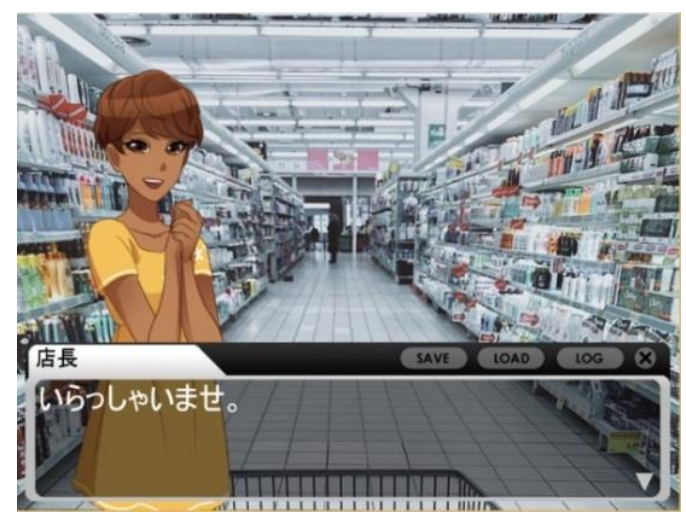

Fig. 9. At Supermarket (Level 2)

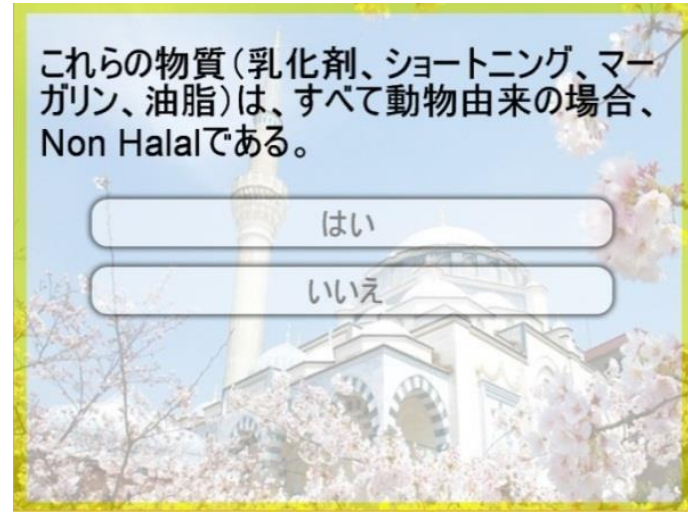

Fig. 10. Questions regarding Halal beverage

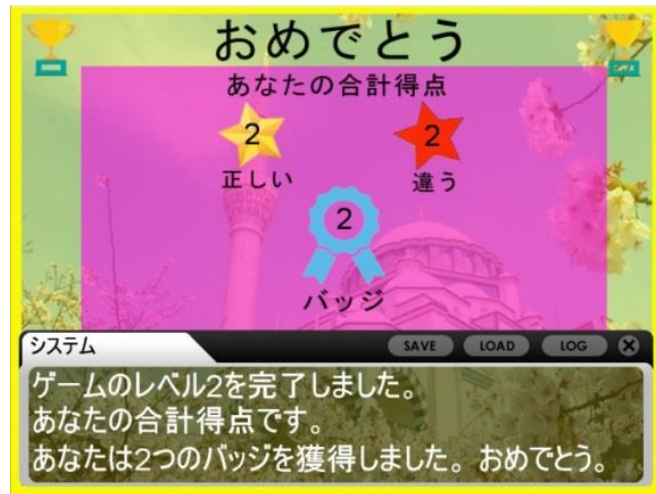

Fig. 11. Complete Level 2 of the games 


\subsection{At meats shop}

At this place, Mr. Fujiwara and the player were served by a butcher of the meat shop (see Figure 12.0). Mr. Fujiwara will bring the player inside the meat shop but before that, he will ask two questions to the player. These two questions were regarding the meats that Haram (Non-Halal) for Muslims to be eaten. If the player manages to answers the question right, he will get a score as 1 and the happy sound was played. If the answer is wrong, he will get a score as 0 and the sad sound was played. For the answer correct or wrong, the results were displayed and explain why it is correct or wrong. Between the first and the second questions, the tips were provided to the payer, to give a clue to the player in answering the questions (see Figure 13.0). After completing this third quiz, the butcher was welcoming them and allows them to enter into the meat shop. They together entered the meat shop and start buying the meats. Here also the player will get Badges to show that he/she completing the third level of the games. The screen then shows a total score of the player (wrong and correct) and also the badges (value set as 3) (see Figure 14.0). The sound of completing level 3 played. In the end, the games will ask the player either to continue playing the games or not. If the player chooses to continue, the games were going back to level 1. If the player chooses to stop, the games will go back to the main page whereby the player can exit the games.

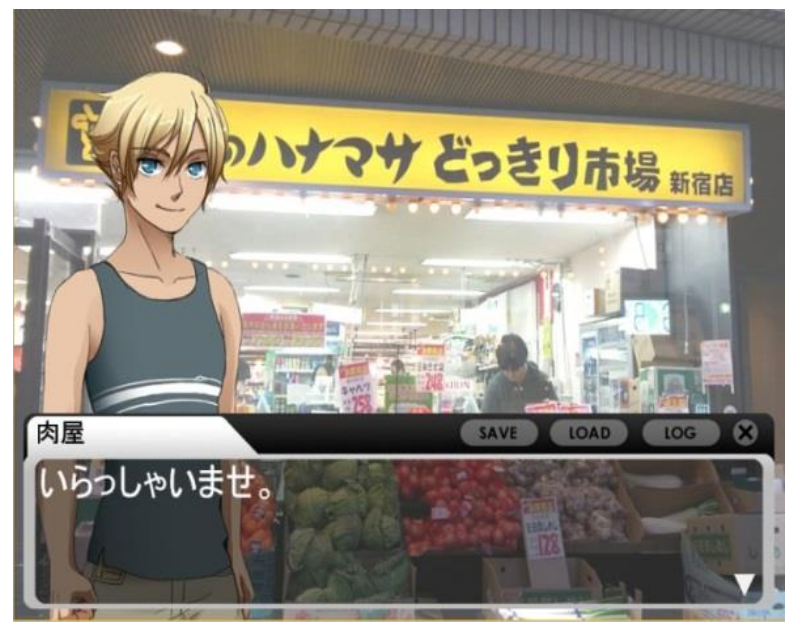

Fig. 12. At Meat shop 


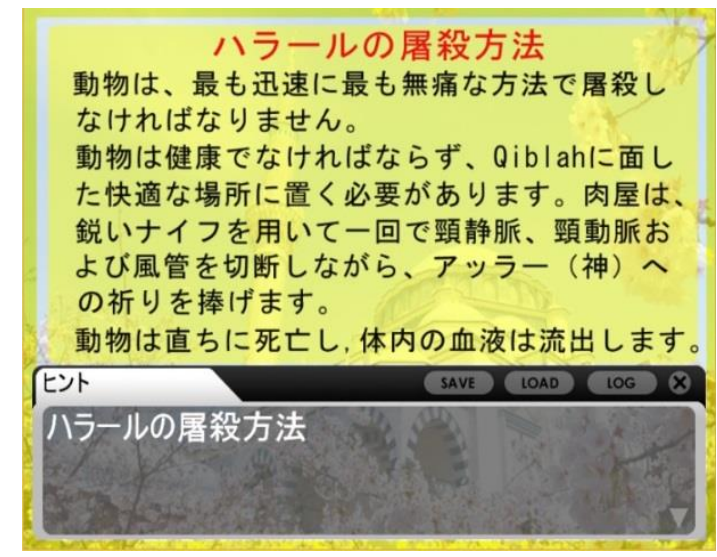

Fig. 13. Tips for the player

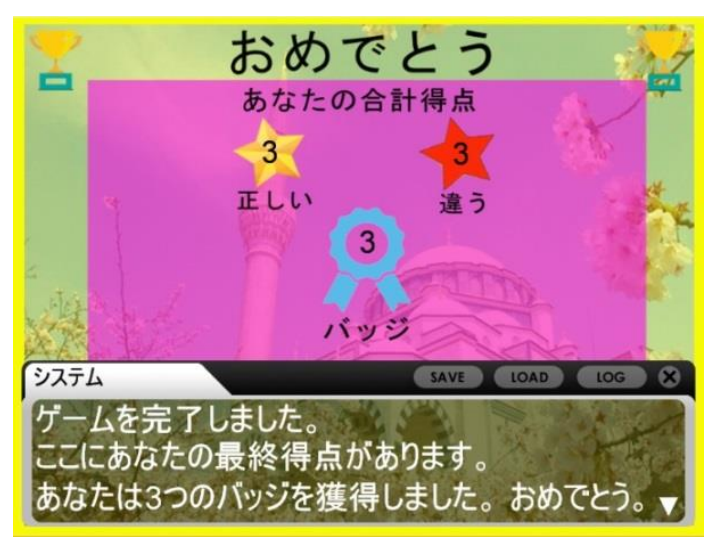

Fig. 14. Complete Level 3 of the games

\section{Conclusion}

In conclusion, the development of MJHG was completed successfully. The procedural and technical steps for the development of MJHG have been discussed. The development methodology used in developing MJHG was the waterfall software development life cycle, which involves five majors' stage which are requirement analysis, system design, implementation, testing, and maintenance. As mentioned earlier, the latest technology and software have been involved in this development including Unity 3D (ver 5.6.3) together with Android SDK, JDK, Unity Extension, Photoshop, and Audacity. To make it MJHG more attractive and alive, multimedia elements included audio, animation, graphics, and image were utilized. All of these elements blending with the gamification elements such as quiz rewards, badges, and feedback to make it as gamified applications. This makes MJHG more fun to play whereby the anime character also was used. The MJHG was design based on the well-known visual novel concept, 
which provides the users three levels of the stories that need to be followed. At each level, the quiz regarding Halal terms was available to be answered and the feedback was given to the users. The user gets the rewards as well as badges after completing them at each level. The emotions of the users such as happy and sad were provided as the audio. Based on all of these capabilities of MJHG, it, therefore, can help the potential users' not only Japanese people but also non-muslim to increase their level of understanding and awareness toward Halal terms.

\section{Acknowledgement}

The authors would like to express their sincere appreciation to Universiti Utara Malaysia, Japan Advanced Institute of Science and Technology (JAIST) and Universiti Sains Islam Malaysia for supporting this study.

\section{$7 \quad$ References}

[1] S. Kim and S. Mercurio, "Muslim in Japan," Tokyo25 July 20172017.

[2] S. M. Yusof and N. Shutto, "The Development of Halal Food Market in Ja-pan: An Exploratory Study," in International Halal Conference, PWTC, Kuala Lumpur, Malaysia, 2012.

[3] Y. A. Adidaya, "Halal in Japan: History, Issues and Problems," Master The-sis, University of Oslo, Norway, 2016.

[4] S. Alhabshi, "Could Japan excel in the Halal Food Industry?" The International Journal Research Publication's, vol. 5, 2016.

[5] J. Majuri, et al., "Gamification of education and learning: A review of empirical literature," in Proceedings of the 2nd International GamiFIN Conference, GamiFIN 2018, 2018.

[6] K. M. Kapp, The gamification of learning and instruction: game-based methods and strategies for training and education: John Wiley \& Sons, 2012.

[7] N. I. Adhani and R. D. R. Awang, "A survey of mobile augmented reality applications," in 1st International Conference on Future Trends in Computing and Communication Technologies, 2012, pp. 89-96.

[8] J. Edmondson, et al., "Next-Generation Mobile Computing," Software, IEEE, vol. 31, pp. 44-47, 2014.

[9] K. Emad and S. Ichimura, "Halal Food Detector for Muslim," Computer Science Department, Tokyo University of Technology, Tokyo 2013.

[10] N. Dali, et al., "Halal Products from The Consumers Perception: An Online Survey," in Islamic Entrepreneurship Conference (iCEPs2007), Kolej Universiti Islam Malaysia, 2007.

[11] M. A. A. Majid, et al., "Issues of halal food implementation in Malaysia," Journal of Applied Environmental and Biological Sciences, vol. 5, pp. 50-56, 2015.

[12] G. Kiryakova, et al., "Gamification in Education," in 9th International Balkan Education and Science Conference, Edirne, Turkey, 2014.

[13] S. Deterding, et al., "From game design elements to gamefulness: defining gamification," in Proceedings of the 15th international academic MindTrek conference: Envisioning future media environments, 2011, pp. 9-15. https://doi.org/10.1145/2181037.2181 040

[14] G. Zichermann and C. Cunningham, Gamification by design: Implementing game mechanics in web and mobile apps: "O’Reilly Media, Inc.", 2011. 
[15] K. Seaborn and D. I. Fels, "Gamification in theory and action: A survey," In-ternational Journal of human-computer studies, vol. 74, pp. 14-31, 2015. https://doi.org/10. 1016/j.ijhcs.2014.09.006

[16] S. M. Sarif, et al., "Makan@Local Chatok: Mobile Eatery Recommendation System Based on Local Knowledge," International Journal of Interactive Mobile Technologies (iJIM), vol. 14, p. 21, 2020-04-07 2020. https://doi.org/10.3991/ijim.v14i05.13357

[17] N. A. Mohd Rashid, et al., "The Role of Game Elements in Improving Jawi Skills through a Mobile Game 'G-Jawi'," International Journal of Interactive Mobile Technologies (iJIM), vol. 12, p. 11, 2018-11-08 2018. https://doi.org/10.3991/ijim.v12i7.9636

[18] D. Prott and M. Ebner, "The Use of Gamification in Gastronomic Questionnaires," International Journal of Interactive Mobile Technologies (iJIM), vol. 14, p. 18, 2020-02-10 2020. https://doi.org/10.3991/ijim.v14i02.11695

[19] M. Xiao, et al., "Online task assignment for crowdsensing in predictable mobile social networks," IEEE Transactions on Mobile Computing, vol. 16, pp. 2306-2320, 2016. https://doi.org/10.1109/tmc.2016.2616473

[20] J. Rude. (2017, 19 November 2019). New Trends in Education Will Shape How People Are Learning. Available: https://blog.euromonitor.com/new-trends-education-learning

[21] M. B. Blake. (2017) Next Generation of Mobile Devices. IEEE Internet Computing.

\section{Authors}

Ruzinoor Che Mat is an Associate Professor at the School of Creative Industry Management and Performing Arts (SCIMPA), Universiti Utara Malaysia (UUM). His highest position in UUM appointed as Deputy Director of Professional and Continuing Education Centre (PACE) UUM for about 3 years. He holds a PhD in GIS and Geomatic Engineering from Universiti Putra Malaysia (UPM) and MSc. Computer Graphics and Virtual Environment from University of Hull, United Kingdom. He received BEng (Hons.) Electrical and Electronic Engineering from Coventry University, United Kingdom. He has published more than 80 articles in indexed and non-indexed journals including proceedings. He also produced academic books and a reviewer of several high impact journals such as on Remote Sensing and GIS. He is actively involved in presenting papers at national and international levels. He has led and members for about 30 research grants awarded by UUM, Ministry of Education and private institutions. His research interest includes 3D GIS, terrain visualization, game engines, remote sensing and GIS application, Virtual Reality, Augmented Reality, Gamification, computer graphics and visualization. Email: ruzinoor@gmail.com

Kazunori Miyata has been a Professor at the Japan Advanced Institute of Science and Technology (JAIST) since 2002. Prior to joining JAIST, he was an Associate Professor in the Department of Imaging Art at the Tokyo Institute of Polytechnics (19982002), and researcher at IBM Japan (1984-1998). He received his B.S. degree from Tohoku University in 1984, and his M.S. and Ph.D. from the Tokyo Institute of Technology in 1986 and 1997. His research interest includes computer graphics, media art, and multimedia applications. He was the 4th president of the Society for Art and Science, Japan. He is a member of ACM and IEEE.

Azman Ab Rahman is an Associate Professor at the Faculty of Shariah and Law, University of Islamic Sciences Malaysia (USIM) and holds position as Deputy Director 
at World Fatwa Research and Management Institute (INFAD) USIM. He holds a Bachelor Degree from the University of al Al-Bayt, Mafraq, Jordan in the field of Fiqh and the Fiqh Proposal. He obtained a Masters and Doctor of Philosophy from the International Islamic University of Malaysia (UIAM) in the field of Fiqh and Usul Fiqh. He has published more than 100 articles in indexed and non-indexed journals and also produced more than 50 academic books in the field of zakat and contemporary fiqh. He is actively involved in presenting papers at national and international levels. He has led 40 research grants and member for more than 70 research projects including research grants awarded by USIM, Ministry of Education, Department of Prime Minister, other state agencies and private institutions. His outstanding outputs in research were evident from his receiving distinguished awards at national and international levels. He also actively involved in the development of Islamic games such as Global Zakat Game (GZG), Global Halal Game (GHG), Global Faraid Game (GFG) and others game.

Article submitted 2020-06-26. Resubmitted 2020-07-26. Final acceptance 2020-07-27. Final version published as submitted by the authors. 